\title{
The power of social influence over food intake: examining the effects of attentional bias and impulsivity
}

\author{
Roel C. J. Hermans ${ }^{1 *}$, Junilla K. Larsen ${ }^{1}$, Kirsten Lochbuehler ${ }^{1}$, Chantal Nederkoorn ${ }^{2}$, C. Peter Herman ${ }^{3}$ \\ and Rutger C. M. E. Engels ${ }^{1}$ \\ ${ }^{1}$ Behavioural Science Institute, Radboud University Nijmegen, PO Box 9104, 6500 HE Nijmegen, The Netherlands \\ ${ }^{2}$ Faculty of Psychology and Neuroscience, Maastricht University, PO Box 616, 6200 MD Maastricht, The Netherlands \\ ${ }^{3}$ Department of Psychology, University of Toronto, 100 St. George Street, Toronto, Canada, ON M5S $3 G 3$
}

(Submitted 11 January 2012 - Final revision received 29 February 2012 - Accepted 3 March 2012 - First published online 9 May 2012)

\begin{abstract}
Numerous studies have shown that people adjust their intake directly to that of their eating companions. A potential explanation for this modelling effect is that the eating behaviour of others operates as an external eating cue that stimulates food intake. The present study explored whether this cue-reactive mechanism can account for modelling effects on intake. It was investigated whether attentional bias towards dynamic eating cues and impulsivity would influence the degree of modelling. Participants completed one individual session and one session in which an experimental confederate accompanied them. In the first session, eye movements were recorded as an index of attentional bias to dynamic eating cues. In addition, self-reported impulsivity and response inhibition were assessed. The second session employed a between-participants design with three experimental conditions in which participants were exposed to a same-sex confederate instructed to eat nothing, a low or a large amount of M\&Ms. A total of eighty-five young women participated. The participants' self-reported impulsivity determined the occurrence of modelling; only low-impulsive women adjusted their intake to that of their eating companion. Attention towards eating cues and response inhibition, however, did not moderate modelling of food intake. The present study suggests that cue-reactive mechanisms may not underlie modelling of food intake. Instead, the results emphasise the importance of social norms in explaining modelling effects, whereas it is suggested that the degree of impulsivity may play a role in whether or not women adhere to the intake norms set by their eating companion.
\end{abstract}

Key words: Modelling: Food intake: Women: Attentional bias: Impulsivity

Food and eating are intertwined with our social lives; mostly, we eat with or in the presence of other people. Therefore, it should not be too surprising that one's eating behaviour is profoundly affected by social factors. Studies have consistently shown that people tend to eat as much or as little as do those with whom they eat ${ }^{(1-3)}$. The process of adjusting one's intake to that of others is often referred to as modelling of food intake. Although these modelling or matching effects have proven to be very powerful, little is known about the mechanisms underlying these effects.

People's tendency to adapt their intake to that of others is often attributed to one's concern with what their eating behaviour is communicating to others ${ }^{(4)}$. Herman et al. ${ }^{(5)}$ have suggested a normative model which posits that people use others' intake as a way of determining how much they may eat without appearing to eat excessively. Thus, people use the intake of others as an example of 'appropriate eating' and adjust their own level of intake accordingly. A limitation of this normative framework, however, is that it gives little insight into whether there is any particular characteristic that makes some people more or less susceptible to the effect of modelling on intake. Because an individual's intake is multiply determined, it is important to consider other mechanisms that may affect eating (and subsequent modelling behaviour).

If the eating behaviours of others are construed as an external eating cue that may stimulate food intake ${ }^{(6)}$, there might be large individual variation in the intensity of responsiveness to this dynamic eating cue. Thus, in addition to the normative framework, it is also possible that a cue-reactivity model ${ }^{(7)}$ may help to explain modelling effects. It must be acknowledged that there is a distinction between food cues per se (i.e. sight, smell or taste of food) and dynamic eating cues (e.g. the sight of someone eating). That is, dynamic eating cues probably can never be entirely separated from food

Abbreviation: BIS, Barratt Impulsiveness Scale.

*Corresponding author: Dr R. C. J. Hermans, fax +3124 3612776, email r.hermans@bsi.ru.nl 
cues per se, because the sight of someone eating almost necessarily involves the sight of the food that is being eaten. The principal aim of the present study is to explore whether a cue-reactive mechanism can (at least partially) explain modelling of food intake. Therefore, two individual-difference moderators (i.e. attentional bias to dynamic eating cues and impulsivity) that might influence the extent to which people are likely to increase eating in response to a real-life dynamic eating cue (i.e. the sight of someone eating) were examined.

In an environment which is characterised by an abundance of highly palatable food items and the presence of eating others, people are frequently exposed to attractive food or eating cues. Although this may generally lead to an increased temptation to indulge ${ }^{(8)}$, not everyone is equally susceptible to these temptations ${ }^{(9)}$. Some individuals may find food particularly rewarding ${ }^{(10,11)}$ and therefore automatically attend to external food-related cues. Conversely, this tendency to automatically detect and attend to such external food cues may contribute to craving and subsequent (over)eating ${ }^{(12)}$. It has been theorised that these attentional biases for food cues follow from the cues' incentive salience ${ }^{(13,14)}$. According to this incentive-salience theory, as a consequence of classical conditioning, the cue itself is able to produce a conditioned rewarding experience. As a result, these cues gain 'attention grabbing powers', which enable them to capture attention and elicit approach behaviour ${ }^{(14,15)}$. These cues might not only refer to the food itself (i.e. sight, smell or taste of food), but also directly to stimuli associated with the food (e.g. packaging, plates or cutlery) or intake routines (i.e. grabbing or biting the food $)^{(7)}$. The most direct way to assess individual differences in attention towards these cues is to record eye movements during a visual attention paradigm, because this provides a direct, observable, dynamic and ecologically valid measure of visual attention processes ${ }^{(16)}$. The existence of attentional biases to passive food cues (i.e. words and pictures) has repeatedly been established among normal- and overweight individuals $^{(12,17)}$. The present study, however, is the first to examine whether attentional biases towards dynamic eating cues moderate modelling effects on food intake. Because of the prevalence of dynamic eating cues in our current 'toxic environment $^{\text {,(18) }}$, it is important to examine whether individuals' attention to these cues may affect modelling of food intake.

Another factor that might moderate people's food intake in response to the sight of others eating is impulsivity. Impulsivity is generally defined as the tendency to think, control and plan insufficiently, which often results in maladaptive or inaccurate responses ${ }^{(19)}$. Although impulsive behaviours can be very diverse, scholars have distinguished three important aspects of impulsivity. The first aspect is impulsiveness, which was defined by Eysenck et $a l^{(20)}$ as 'acting in the spur of the moment without being aware of any risk involved' (p. 315) and is often measured by self-report. The second aspect is response inhibition, an executive function which is assumed to be at the heart of impulsive behaviour ${ }^{(21)}$. Response inhibition is needed to overrule impulsive reactions in order to regulate long-term goals and standards ${ }^{(22)}$ and is measured by behavioural tasks. The third aspect is rewardrelated impulsivity, which can be measured by behavioural tasks and self-reports. Reward-sensitive people detect more rewarding stimuli and are more likely to approach these stimuli ${ }^{(23)}$. In the context of the present study, we chose to focus on (self-reported) impulsiveness and response inhibition, but not on reward sensitivity. To date, numerous studies have been conducted on the influence of both aspects of impulsivity on food intake. For example, Guerrieri et al. ${ }^{(24)}$ found that high-impulsive women consumed more than did less impulsive women when confronted with palatable food (during a taste task), but these effects were only found when participants were categorised based on the self-report measure of impulsivity as opposed to the behavioural measure. In another study, however, the same authors demonstrated that both measures of impulsivity predicted food intake in normal-weight healthy women ${ }^{(25)}$. Likewise, Jansen et al. ${ }^{(26)}$ found that restrained eaters ate more in response to smelling palatable food but only if they were deficient in their response inhibition. Finally, it has been found that experimentally inducing a lack of control by manipulating response inhibition increased food intake among normal-weight women ${ }^{(27,28)}$, In sum, both impulsiveness and response inhibition seem to be linked to reactions to palatable food. Thus, it might be harder for high-impulsive people to control food intake in response to food cues (e.g. the smell and availability of food) than it is for low-impulsive people. However, one area that has not been studied is whether impulsiveness and response inhibition also affect the extent to which people are likely to increase eating in response to the sight of someone eating.

The present study aimed to explore whether a cue-reactive mechanism can account for modelling of food intake. It was investigated whether attentional bias towards dynamic eating cues and impulsivity would influence people's modelling of food intake. As in most previous studies that examined modelling of food intake (for example, Herman et al. ${ }^{(5)}$ ), the focus was exclusively on females. Because food intake is triggered by the exposure to external cues ${ }^{(29)}$ and a positive relationship is proposed between food-related attention and food intake $^{(13,14,16)}$, it was hypothesised that women with an attentional bias towards eating cues would be more likely to model the eating behaviour of a same-sex confederate. Most researchers have monitored participants' attention as they complete a visual probe task in which food-related and matched control pictures compete for participants' attention ${ }^{(12,17,30)}$. To increase ecological validity, however, women's attention while watching a movie with dynamic eating cues was investigated. Second, it was hypothesised that impulsive women would be more likely to model the intake of their eating companion than low-impulsive women, as they may be less able to control their impulses in response to real-life dynamic eating cues.

\section{Experimental methods}

\section{Design}

Participants had to complete two testing sessions: one individual session and one session in which they were accompanied by an experimental confederate (eating partner). In the 
first individual session, participants filled out a series of questionnaires and afterwards watched a movie while their eye movements were recorded with an eye tracker. At the end of this session, participants' response inhibition was assessed. The second session employed a between-participants design with three experimental conditions in which the participants were exposed to a female confederate who was instructed to eat nothing (no-intake confederate condition), or four M\&Ms (181.55 kJ; low-intake confederate condition) or twenty-four M\&Ms (1089.29 kJ; high-intake confederate condition). On average, there were 5 (SD 4) d between the first and second session.

\section{Participants and confederates}

The sample consisted of eighty-five participants with a mean age of $20 \cdot 20$ (SD 1.85) years and a mean BMI of 22.38 (SD $2 \cdot 26) \mathrm{kg} / \mathrm{m}^{2}$. In our sample, $88 \%$ of the women had a normal weight and $12 \%$ were overweight. In the second session, five female students acted as confederates. They had a mean age of 21.40 (SD 1.52) years and a mean BMI of 20.74 (SD 1.33$) \mathrm{kg} / \mathrm{m}^{2}$. Confederates were instructed not to make any remarks on the taste, colour or palatability of the M\&Ms, or to offer participants any M\&Ms. Each confederate served in each condition several times.

\section{Materials and measures}

In the first individual session, an eye-tracker paradigm was used in which the participants' eye movements were recorded as a direct measure of their attention towards dynamic food cues (i.e. the sight of others eating). The stimulus material consisted of 17 min of the movie 'Eat Pray Love' (2010). In this movie, the main female character (Julia Roberts) starts a journey around the world that becomes a quest for self-discovery. The first part of the movie, in which she discovers the true pleasure of nourishment by eating in Italy, was used. A total of fifty-one scenes were selected in which ample food-related cues are depicted (range in ms is 600-24760). Food-related cues were mainly portrayed in the form of the protagonist eating highly palatable foods (alone or with others). The participants' eye movements while watching the movie clip were recorded with a corneal reflection eye tracker (Tobii T120 Eye Tracker; Tobbii Technology). The gaze of each participant was calibrated before testing. For more detailed information on the calibration and specific eye-tracking procedure, see Lochbuehler et $a l .{ }^{(31)}$. For each scene, the area of interest was defined. This area was restricted to the display of an eating cue, which means that a fixation took place only if at least one of the participant's eyes overlapped with the display of an eating cue (i.e. food or a person eating). Each scene was coded as to whether there was a fixation or non-fixation on the cue or whether data were missing. For this purpose, two coders, who were blind to our research questions, independently coded the participants' data. The intra-class correlation coefficient was 0.95 for the number of fixations, 0.90 for the gaze duration measures and 0.98 for the initial fixation measures.

\section{Attentional bias for food cues}

To measure the participants' attention to food-related cues, three dependent variables were used: (1) the number of fixations on the food-related cues, (2) the duration of fixations (i.e. gaze duration), and (3) the latency of initial fixations on the food-related cues (see Mogg et al. ${ }^{(16)}$, Lochbuehler et $a l^{(31)}$ and Field et $\left.a l .{ }^{(32)}\right)$. A participant's number of fixations was determined by counting the total number of times the participant fixated on the food cues. A participant's gaze duration was defined as the overall amount of time that the participant's gaze was directed to the food cues. A participant's initial fixation was defined by the time of the first fixation of the cue after its appearance. These three variables for each participant for each of the fifty-one scenes were assessed. In the main analyses, then, the overall scores of all scenes (for each variable separately) were used.

\section{Self-reported impulsivity}

The Barratt Impulsiveness Scale (BIS) ${ }^{(33)}$ was used to measure trait impulsiveness. Examples of items were 'I don't pay attention' and 'I like to think about complex problems'. The scale consists of thirty items rated on a four-point scale, with possible scores ranging from 30 to 120 . Higher scores indicate more impulsiveness. Cronbach's $\alpha$ was $0 \cdot 72$.

\section{Response inhibition}

The stop-signal task ${ }^{(34)}$ was used to measure response inhibition. Response inhibition, as measured with this task, has been shown to be related to impulsivity. The stop-signal task is a choice reaction time task in which the participants should respond as fast as possible to a visual go-signal (an X or an O), unless an auditory stop signal is presented (through headphones), in which case the response should be inhibited (25\% of the trials). For more detailed information on this task, see Nederkoorn et $a l .{ }^{(35)}$. Participants completed two practice blocks without stop signals and one with stop signals. Next, they completed four test blocks of 128 trials successively. The two variables measured in this task are reaction time and mean stop delay. The stop-signal reaction time (in ms) was calculated by subtracting the stop delay from reaction time. Higher stop-signal reaction times indicate less inhibitory control.

\section{Hunger}

A visual analogue scale $(140 \mathrm{~mm})$ was used to measure the extent to which the participants felt 'satisfied' or 'hungry' before the second session. To avoid demand characteristics, the participants' hunger level after the experimental manipulation was assessed (see also Anschutz et al. ${ }^{(36)}$ and Hermans et $\left.a{ }^{(37)}\right)$.

\section{Liking of the test food}

Participants reported their liking of the available chocolatecoated peanuts on a ten-point scale from 'did not like it at all' to 'liked it very much'. 


\section{Participants' awareness of confederate's intake}

To measure the participants' awareness of the confederate's intake, participants were asked to indicate how many M\&Ms the other person had eaten (see Hermans et $a l .{ }^{(37)}$ ).

\section{Actual food intake}

Participants' actual food intake in the break of the second session was measured by counting the total number of M\&Ms consumed by each participant. The total quantity of snack food consumed (i.e. single pieces of M\&Ms) was used as the dependent variable.

\section{Procedures}

The first individual session lasted approximately $45 \mathrm{~min}$. After entering the laboratory, participants were asked to fill out a series of questionnaires, after which they were told that they would watch a segment of the contemporary movie 'Eat Pray Love' ( (C) 2010 Columbia Pictures Industries, Inc.). Participants were seated in a chair, $60 \mathrm{~cm}$ in front of the eye tracker so that their eye movements could be recorded while they watched the movie. They were instructed to find a comfortable position in which they could watch the movie in a relaxed way without moving. After the participants were successfully calibrated, the experimenter left the room. After they watched the movie, the participants completed the stop-signal task, which lasted approximately $20 \mathrm{~min}$. Next, the participants were requested to complete a questionnaire in which, among other measures, self-reported impulsivity was assessed with the BIS. Finally, their height and weight were measured in order to calculate their BMI (calculated as $\mathrm{kg} / \mathrm{m}^{2}$ ). In order to simulate a naturalistic eating context, the second session took place in a laboratory furnished as an ordinary living room. During this session, participants were paired with a female confederate with whom they had to spend an experimental break during the interval between two bogus tasks. This session lasted approximately $30 \mathrm{~min}$. Participants received course credits or payment $(€ 15)$ after they volunteered for both sessions. Debriefing took place after the data collection for the entire experiment. The present study was conducted according to the guidelines laid down in the Declaration of Helsinki and all procedures involving human subjects were approved by the Ethics committee of the Faculty of Social Sciences of the Radboud University Nijmegen. Written informed consent was obtained from all subjects.

\section{Analytic strategy}

Data were analysed using SPSS for Windows (version 17.0, 2008; SPSS, Inc.). $\alpha$ was set at $P<0.05$. Originally, the sample consisted of 100 female undergraduate students. However, fifteen participants were excluded from the analyses. The eye-tracking data of eleven participants could not be analysed because more than $50 \%$ of their data were missing (due to calibration problems); and four participants had to be excluded because they reported an allergy to peanuts and therefore could not eat from the available test food in the second session. First, using one-way ANOVA, we checked whether there were any differences in BMI, hunger level, self-reported impulsivity, response inhibition and attention to food-related cues (all three measures) between conditions. If they were significantly correlated with food intake, BMI, hunger level and liking of the test food were entered into the model as covariates. To answer the main questions, separate ANCOVA were used to examine the main and interaction effects of the modelling manipulations, the impulsivity and the attentional attention bias measures on the participants' total food intake (in single pieces of M\&Ms). Cohen's $f$ was used to indicate the effect size of the main effect of the modelling manipulations, because we had more than two conditions in our design ${ }^{(38)}$. Effect sizes of $0.02,0.15$ and 0.35 are termed small, medium and large, respectively ${ }^{(38)}$.

\section{Results}

\section{Individual characteristics}

Participants' BMI, hunger level, self-reported impulsivity, response inhibition and attention to food-related cues did not differ across the three confederate's intake conditions (all $P>0.05$ ). Table 1 displays the participants' characteristics across the conditions. All measures used in the present study were included in a correlation matrix (see Table 2). BMI $\left(r_{85}-0.28, P<0.05\right)$ and participants' liking of the test food $\left(r_{85} 0.32, P<0 \cdot 01\right)$ were significantly correlated with actual food intake during the second session and therefore entered into our model as covariates. It should be noted that the results remained the same when these variables were not included in the main analyses.

\section{Main effect of confederate's intake on participants' intake}

A significant difference in intake was found among the participants in the three intake conditions $\left(F_{2,80}=8.49, P<0.001\right.$, $f^{2}=0.46$ ), while controlling for the participants' BMI and liking of the test food. When exposed to a high-intake confederate, the participants consumed significantly more M\&Ms than they did when exposed to a low-intake confederate $(P<0.05)$ or no-intake confederate $(P<0 \cdot 001)$. Participants consumed a mean of 1.82 M\&Ms $(45.39 \mathrm{~kJ}$; SE 1.07$)$ when exposed to a confederate eating nothing (no intake), 3.94 M\&Ms (178.83 kJ; sE 1.13$)$ when exposed to a confederate eating four M\&Ms $(181.55 \mathrm{~kJ}$; low intake) and $8.22 \mathrm{M} \& \mathrm{Ms}$ $(373.08 \mathrm{~kJ}$; SE 1.11$)$ when exposed to a confederate eating twenty-four M\&Ms $(1089.29 \mathrm{~kJ}$; high intake). Of the participants, forty-one (48\%) did not eat any M\&Ms, twenty-five of them in the no-intake condition.

\section{Moderating effects of attentional bias to dynamic food cues on modelling of intake}

To examine the moderating effects of attention (i.e. number of fixations, gaze duration and initial fixations), we performed three separate ANCOVA with each of the attention measures 
Table 1. Characteristics of the study population by condition

(Mean values and standard deviations)

\begin{tabular}{|c|c|c|c|c|c|c|c|c|}
\hline & \multicolumn{8}{|c|}{ Condition } \\
\hline & \multicolumn{2}{|c|}{ Total } & \multicolumn{2}{|c|}{ No intake } & \multicolumn{2}{|c|}{ Low intake } & \multicolumn{2}{|c|}{ High intake } \\
\hline & Mean & SD & Mean & SD & Mean & SD & Mean & SD \\
\hline$n$ & \multicolumn{2}{|c|}{85} & \multicolumn{2}{|c|}{31} & \multicolumn{2}{|c|}{26} & \multicolumn{2}{|c|}{28} \\
\hline Age (years) & $20 \cdot 20$ & 1.85 & $20 \cdot 19$ & 1.97 & 19.88 & 1.53 & $20 \cdot 50$ & 1.99 \\
\hline $\mathrm{BMI}\left(\mathrm{kg} / \mathrm{m}^{2}\right)$ & 22.38 & $2 \cdot 26$ & 23.04 & 2.53 & 22.29 & $2 \cdot 31$ & 21.72 & 1.70 \\
\hline Liking of the test food & 6.98 & 2.35 & $6 \cdot 26$ & 2.58 & $7 \cdot 23$ & $2 \cdot 41$ & 7.53 & 1.84 \\
\hline $\mathrm{BIS}$ & $63 \cdot 22$ & $7 \cdot 47$ & 61.42 & 7.02 & 63.77 & 6.95 & 64.71 & 8.24 \\
\hline SSRT & $224 \cdot 35$ & $26 \cdot 82$ & 225.98 & 35.48 & $236 \cdot 20$ & 44.98 & 211.53 & 25.58 \\
\hline AB-measure $1^{*}$ & 50.69 & $15 \cdot 45$ & 51.84 & $12 \cdot 98$ & 46.65 & 15.08 & $53 \cdot 18$ & 17.93 \\
\hline AB-measure $2 \dagger$ & $6 \cdot 35$ & 1.57 & $6 \cdot 41$ & 1.58 & $6 \cdot 30$ & 1.54 & $6 \cdot 34$ & 1.62 \\
\hline AB-measure $3 \ddagger$ & $19 \cdot 78$ & $5 \cdot 61$ & 19.05 & 4.39 & $21 \cdot 22$ & 5.91 & $19 \cdot 25$ & 6.43 \\
\hline
\end{tabular}

BIS, Barratt Impulsiveness Scale; SSRT, stop-signal reaction time; AB, attention bias.

* Number of fixations.

† Gaze duration (ms).

$\ddagger$ Latency of initial fixations.

added as an extra factor to our model (while also controlling for BMI and liking of the test food). First, there was no main effect of the participants' number of fixations on food cues in session one and on participants' intake in session two $\left(F_{1,77}=0.06, P=0.81\right)$, nor was there an interaction between the number of fixations and confederate's intake condition on participants' intake $\left(F_{2,77}=0.72, P=0.49\right)$. Also, there was no main $\left(F_{1,77}=0.02, P=0.89\right)$ or interaction effect ( $\left.F_{2,77}=0.51, P=0.60\right)$ for the participants' gaze duration. Finally, we did not find a main $\left(F_{1,77}=1 \cdot 50, P=0.23\right)$ or interaction effect $\left(F_{2,77}=1 \cdot 25, P=0 \cdot 29\right)$ of the participants' initial fixation on participants' actual food intake or participants' modelling behaviour.

\section{Moderating effects of response inhibition and self- reported impulsivity on modelling of food intake}

To examine the moderating effect of response inhibition on participants' modelling of food intake, we added the stopsignal reaction time-score as a factor to our model. Neither the influence of response inhibition on actual food intake $\left(F_{1,72}=1 \cdot 83, \quad P=0 \cdot 18\right)$ nor an interaction $\left(F_{2,72}=2 \cdot 09\right.$, $P=0 \cdot 13)$ between response inhibition and confederate's intake on participants' actual food intake was found.

To examine the moderating effect of self-reported impulsiveness on participants' modelling of food intake, we added the BIS total score as a covariate to our model. No main effect of self-reported impulsiveness on intake was found $\left(F_{1,77}=1.66, \quad P>0.20\right)$. However, a significant interaction between confederate's intake condition and participants' self-reported impulsiveness was found $\left(F_{2,77}=4.32\right.$, $P<0.05)$. To clarify the interaction, we used a median split (median 61) of the BIS score to differentiate low-impulsive participants from high-impulsive participants. The pattern of the interaction indicates that the customary modelling effect was found among the low-impulsive participants $\left(F_{2,38}=10.97, P<0.001\right)$ but not among the high-impulsive participants $\left(F_{2,37}=1 \cdot 01, P>0 \cdot 20\right)$, indicating that only the low impulsives modelled the food intake of their eating companion (i.e. eating more or less when the other ate more or less). The difference in intake between the low and high impulsives was particularly evident in the high-intake condition. In this condition, low impulsives ate an average of $11.52 \mathrm{M} \& \mathrm{Ms}(522.26 \mathrm{~kJ}$; SE 1.52$)$, whereas high impulsives only ate $4.60 \mathrm{M} \& \mathrm{Ms}(208.78 \mathrm{~kJ}$; SE 1.51) (see Table 3). Additionally, it was checked whether the low and high impulsives differed in their estimations of the confederate's number of M\&Ms consumed in the high-intake condition. When exposed to a confederate eating twenty-four M\&Ms, low impulsives indicated that the confederate consumed approximately seventeen M\&Ms, whereas the high impulsives

Table 2. Pearson's product-moment correlations between actual food intake, BMI, self-report impulsiveness, behavioural impulsivity and the three attention bias $(A B)$ measures

\begin{tabular}{|c|c|c|c|c|c|c|c|}
\hline & Food intake & $\begin{array}{c}\text { Self-report } \\
\text { impulsiveness }\end{array}$ & $\begin{array}{l}\text { Behavioural } \\
\text { impulsivity }\end{array}$ & BMI & AB-measure 1 & AB-measure 2 & AB-measure 3 \\
\hline Food intake & - & & & & & & \\
\hline Self-report impulsiveness & -0.07 & - & & & & & \\
\hline Behavioural impulsivity & -0.16 & 0.06 & - & & & & \\
\hline BMI $\left(\mathrm{kg} / \mathrm{m}^{2}\right)$ & $-0.28^{*}$ & -0.07 & 0.12 & - & & & \\
\hline$A B$-measure 1 & -0.01 & -0.24 & $-0 \cdot 10$ & 0.14 & - & & \\
\hline AB-measure 2 & 0.02 & -0.04 & -0.01 & 0.01 & $0.66^{\star *}$ & - & \\
\hline AB-measure 3 & 0.15 & 0.00 & 0.02 & -0.09 & $-0 \cdot 30^{\star \star}$ & $-0.38^{\star \star}$ & - \\
\hline
\end{tabular}

Correlation is significant: ${ }^{\star} P<0.05,{ }^{\star \star} P<0.01$ (two-tailed). 
indicated that the confederate consumed approximately ten M\&Ms $(P=0.05)$.

\section{Discussion}

As yet, little is known about the mechanisms underlying modelling of food intake. The present study aimed to explore whether a cue-reactive mechanism can (at least partially) explain modelling of food intake. It was investigated whether attentional bias towards eating cues and the degree of impulsivity influenced young women's modelling of food intake. The results confirmed previous findings that young women adjust their intake to that of others ${ }^{(1-3)}$. The present study adds to this basic finding the discovery that self-reported impulsivity can moderate this modelling effect. In contrast to our hypothesis, however, only low-impulsive women modelled the intake of their eating companion. Participants' attention towards eating cues and response inhibition did not moderate modelling effects on food intake.

In line with the extensive literature on the effects of foodcue exposure on food intake ${ }^{(7)}$, it was hypothesised that the eating behaviour of another person could serve as a powerful stimulating eating cue, in particular for women with an enhanced attention bias. However, no relationship was found between women's attention towards dynamic eating cues and the likelihood of modelling: women with enhanced attention for eating cues did not display greater modelling than did those who paid less attention to these eating cues. Furthermore, no differences in overall intake were found between women with different attention levels. These findings suggest that individual differences in attention towards eating cues are overruled by a general tendency to adhere to socially derived norms of appropriateness. Thus, in spite of variations in attention towards food-related cues, women are likely to adapt their intake to that of others. Another possibility is that individual differences in attention were restricted in range and therefore did not exert a discernible effect. The present study focused on (mainly) normal-weight women. Previous research has shown that overweight or obese people exhibit an enhanced attentional bias to food-related stimuli compared with normal-weight individuals ${ }^{(17,30)}$. It is possible that a causal link between attention towards eating cues and modelling may be observed only among overweight or obese individuals, as they are generally more vulnerable to food cues. Finally, the dynamic sight of someone eating might have lower 'attention grabbing powers' than attention

Table 3. Total number of M\&Ms consumed in the different conditions by participants with different levels of self-reported impulsivity (Mean values and standard errors)

\begin{tabular}{lrrrrrr}
\hline & \multicolumn{2}{c}{ Low impulsivity } & & \multicolumn{2}{l}{ High impulsivity } \\
\cline { 2 - 3 } & \multicolumn{2}{c}{ Mean } & SE & & Mean & SE \\
\hline No-intake confederate condition & 1.58 & 1.42 & & 1.85 & 1.44 \\
Low-intake confederate condition & 3.58 & 1.59 & & 4.30 & 1.47 \\
High-intake confederate condition & 11.42 & 1.46 & & 4.73 & 1.52 \\
\hline
\end{tabular}

for passive food cues (i.e. words or pictures) as measured in traditional food-related Stroop or dot-probe tasks and could therefore be easily overwhelmed by other external influences (e.g. social norms).

Although the present results are justifying the generalisation that young women eat more when their eating companions eat more, it was found that the overall degree of intake was relatively low. At best, participants consumed a mean number of eight M\&Ms, which is still considerably lower than the intake of the large-eating companion (who ate twenty-four M\&Ms). Albeit this finding is not uncommon in the literature on social modelling on food intake ${ }^{(1,39)}$ and non-social factors such as sensory-specific satiety might have been responsible for these patterns of findings ${ }^{(40)}$, it might also be that the intake of the eating companion rather inhibits than stimulates people to eat. This accords with previous modelling research that shows that minimal eating companions produce the most significant change in eating quantity ${ }^{(41,42)}$. Determining whether specific individuals regard the intake of others as an inhibiting or stimulating cue would require future research, in which people are asked to report their eating motivations in a social context. It should be noted, however, that such explorations are rendered difficult, because psychological states that occur during social interactions are difficult to identify as people are often unaware of their own intentions in this regard ${ }^{(43)}$. Next, this line of research would benefit from including a control condition in which participants eat alone in order to make definitive statements about whether the intake of others increases or decreases one's intake.

If the eating behaviour of others acts as an inhibiting rather than a stimulating cue, this might also explain our unexpected impulsivity finding. It has been proposed that an individual's inhibitory control system may override the motivation to consume food and makes it possible for more deliberate longterm goals to predominate. In the context of consummatory behaviour, such goals often reflect health concerns or social norms ${ }^{(35)}$. Thus, for low-impulsive women who are generally well controlled, it may be easier to control their intake in the presence of palatable food and conform to the behaviour of others in order to fulfil more deliberate goals, such as avoiding negative stereotypes or gaining social approval or acceptance $^{(44-46)}$. Highly impulsive women, however, were found to eat the same amount regardless of whether their eating companion was eating a lot or a little, which suggests that they were less inclined to follow the other's intake. In this context, however, we might have expected to find the highly impulsive women to eat uniformly more than their eating companion, but this was not supported by our data. Why did they eat so little? It is possible that the high impulsives focused more on the bowl of M\&Ms than on the other's intake, which may have facilitated the subsequent use of counteractive control strategies to resist overconsumption. Overweight people show a characteristic pattern of initial automatic orientation towards food cues and a subsequent voluntary attentional shift away from food ${ }^{(12)}$. Considering the link between obesity and impulsivity ${ }^{(47,48)}$, it is possible that the same approach-avoidance pattern might also have 
accounted for the relatively low intake among the high impulsives, in particular when exposed to a peer eating a large amount of snack food. The fact that the high impulsives were less accurate in their estimations of the amount eaten by the high-intake companion than were low impulsives and, thus, seemingly paid less attention to the intake of the other person might support this assumption. Another explanation is that the bowl of M\&Ms did not have enough sensory impact to stimulate food intake or to reduce counteractive control strategies in response to a stranger who is eating a large amount of food. It is possible that we might have found a different result if we had used food with stronger sensory properties, such as pizza slices, fries or freshly baked cookies.

Although self-reported impulsivity was found to be related to modelling, we were not able to demonstrate the same effects for response inhibition. A few possible explanations are offered here. First, this behavioural measure might not have been sensitive enough to detect differences in a nonclinical population (i.e. normal-weight women) ${ }^{(24,49)}$. Yet, because the effects were in the same direction and showed a trend towards significance, we are likely to assume that women with effective response inhibition may also be more likely to model their intake on that of others. It is possible, however, that the effects of response inhibition are noticeable only in long-term food intake patterns ${ }^{(50)}$ and not in a short time period such as that measured in the present study. Furthermore, because there were some days between the two experimental sessions, participants' response inhibition was actually conceptualised as a trait, whereas it may also be a state $^{(25)}$. Therefore, it is possible that some participants lacked inhibitory control in the first session, but they were able to control their impulses in the second ad libitum eating context, explaining the missing link between response inhibition and modelling of food intake.

Some limitations of the present study should be noted. First, just like the behavioural measure of impulsivity, the participants' attention towards eating cues was also conceptualised as a trait instead of a state. It is known that attention biases and craving are reciprocally related ${ }^{(15,51)}$, and therefore it is possible that an elevated attention to eating cues may not explain people's response to the eating behaviour of others a few days later. However, cognitive biases towards food stimuli are ubiquitous and there is evidence that such biases arise in particular for people with certain trait characteristics, such as being an external eater ${ }^{(52)}$ or restrained eater ${ }^{(53)}$. Second, although we enhanced the ecological validity of the present study by measuring the participants' attention towards dynamic food cues embedded in a larger context, it remains unclear whether participants are more likely to attend to the eater or to the food and how this difference might influence subsequent modelling behaviour. The problem, however, is that foodrelated cues (i.e. properties that refer to food itself) and eating cues (i.e. the eating behaviour of another person) usually go together, and therefore it is difficult to examine their independent contributions. Nevertheless, it appears worth investigating participants' specific attention towards the eating behaviour of others and its influence on subsequent modelling behaviour. Another point for consideration involves the fact that only impulsiveness and response inhibition were measured in the present study. To further understand the link between impulsivity and modelling of food intake, it might also be important to focus on the possible moderating role of reward sensitivity. Future research might examine how reward-sensitive people react to the sight of eating others. If they detect more rewarding stimuli and are more likely to approach these stimuli, it is possible that a different pattern of results might have appeared when measuring this aspect of impulsivity. Finally, contemporary dual-process models propose that an individual's eating behaviour is guided by two distinct cognitive systems that interact with each other: one system operating through fast, automatic impulses, and another system determining whether these automatic impulses are controlled ${ }^{(54)}$. Although our sample was large enough to examine main and interaction effects of both impulsivity and attentional bias, the present study was insufficiently powered to investigate the combination of attentional bias and response inhibition in the interaction with modelling of food intake. Future research may benefit from using a dualistic model approach focusing on this interaction to explain modelling of food intake.

In conclusion, the results of the present study may provide further insight into the possible mechanisms underlying modelling of food intake. On the basis of the present findings, we are likely to suggest that cue-reactive mechanisms may not be helpful in explaining modelling of food intake. Instead, we propose that a normative explanation may best explain people's tendency to adjust their intake to that of others. It was found that only low-impulsive women who are generally well controlled are able to follow the intake of their eating companion and adhere to the norms set by this person. As this is the first study investigating the influence of impulsivity on modelling of food intake, additional research is needed to replicate the present findings and to investigate why lowbut not high-impulsive people are more likely to conform to the eating behaviour of others.

\section{Acknowledgements}

This study was supported by a fellowship grant to J. K. L. from the Netherlands Organization for Scientific Research. All authors declare that they have no relevant financial interests in this study. Furthermore, they certify that there is no personal financial disclosure/conflict of interest. The organisation that has funded the study was not involved in the development of design, collection of the data, writing the paper or decision to submit this paper for publication. The authors would like to thank Hubert Voogd for his technical support in using the eye tracker, and Tine Allards and Jolique Kielstra for their invaluable contributions to coding the data. The authors' responsibilities were as follows: R. C. J. H., J. K. L., R. C. M. E. E. and K. L. contributed to the study conception and design; R. C. J. H. was involved in the acquisition of the data; R. C. J. H., J. K. L. and C. N. participated in the analysis and interpretation of the data; R. C. J. H. was involved in the drafting of the article; C. P. H., C. N. and K. L. participated in 
the critical revision of the manuscript; J. K. L. assisted in supervision. All authors read and approved the final manuscript.

\section{References}

1. Conger JC, Conger AJ, Costanzo PR, et al. (1980) The effect of social cues on the eating behavior of obese and normal subjects. J Pers 48, 258-271.

2. Johnston L (2002) Behavioral mimicry and stigmatization. Soc Cogn 20, 18-35.

3. Hermans RC, Larsen JK, Herman CP, et al. (2012) How much should I eat? Situational norms affect young women's food intake during meal time. Br J Nutr 107, 588-594.

4. Leone T, Herman CP \& Pliner P (2008) Perceptions of undereaters: a matter of perspective? Pers Soc Psychol B 34, $1737-1746$.

5. Herman CP, Roth DA \& Polivy J (2003) Effects of the presence of others on food intake: a normative interpretation. Psychol Bull 129, 873-886.

6. Koh J \& Pliner P (2009) The effects of degree of acquaintance, plate size, and sharing on food intake. Appetite $\mathbf{5 2}$, 595-602.

7. Jansen A (1998) A learning model of binge eating: cue reactivity and cue exposure. Behav Res Ther 36, 257-272.

8. Hill JO \& Peters JC (1998) Environmental contributions to the obesity epidemic. Science 280, 1371-1374.

9. Polivy J, Herman CP \& Coelho JS (2008) Caloric restriction in the presence of attractive food cues: external cues, eating, and weight. Physiol Behav 94, 729-733.

10. Davis C, Patte K, Levitan R, et al. (2007) From motivation to behaviour: a model of reward sensitivity, overeating, and food preferences in the risk profile for obesity. Appetite $\mathbf{4 8}$, $12-19$.

11. Stice E, Spoor S, Ng J, et al. (2009) Relation of obesity to consummatory and anticipatory food reward. Physiol Behav 97, 551-560.

12. Werthmann J, Roefs A, Nederkoorn C, et al. (2011) Can(not) take my eyes off it: attention bias for food in overweight participants. Health Psychol 30, 561-569.

13. Berridge KC (2009) 'Liking' and 'wanting' food rewards: brain substrates and roles in eating disorders. Physiol Behav 97, 537-550.

14. Robinson TE \& Berrdige KC (2003) Addiction. Annu Rev Psychol 54, 25-53.

15. Field M \& Cox WM (2008) Attentional bias in addictive behaviors: a review of its development, causes, and consequences. Drug Alcohol Depend 97, 1-20.

16. Mogg K, Bradley, Field M, et al. (2003) Eye movements to smoking-related pictures in smokers: relationship between attentional biases and implicit and explicit measures of stimulus valence. Addiction 98, 825-836.

17. Castellanos EH, Charboneau E, Dietrich MS, et al. (2009) Obese adults have visual attention bias for food cue images: evidence for altered reward system function. Int J Obes 33, 1063-1073.

18. Schwartz MB \& Puhl R (2003) Childhood obesity: a societal problem to solve. Obes Rev 4, 57-71.

19. Solanto MV, Abikoff H, Sonuga-Barke E, et al. (2001) The ecological validity of delay aversion and response inhibition as measures of impulsivity in $\mathrm{AD} / \mathrm{HD}$ : a supplement to the $\mathrm{NIMH}$ multimodal treatment study of AD/HD. J Abnorm Child Psychol 29, 215-228.

20. Eysenck SGG, Eating G \& Pearson PR (1984) Age norms for impulsiveness, venturesomeness and empathy in children. Pers Indiv Differ 5, 315-321.
21. Barkley RA (1997) Behavioral inhibition, sustained attention, and executive functions: constructing a unifying theory of ADHD. Psychol Bull 121, 65-94.

22. Logan GD \& Cowan WB (1984) On the ability to inhibit thought and action: a theory of an act of control. Psychol Rev 91, 295-327.

23. Avila C (2001) Distinguishing BIS-mediated and BASmediated disinhibition mechanisms: a comparison of disinhibition models of Gray (1981, 1987) and of Patterson and Newman (1993). J Pers Soc Psychol 80, 311-324.

24. Guerrieri R, Nederkoorn C \& Jansen A (2007) How impulsiveness and variety influence food intake in a sample of healthy women. Appetite 48, 119-122.

25. Guerrieri R, Nederkoorn C, Stankiewicz K, et al. (2007) The influence of trait and state impulsivity on food intake in normal-weight healthy women. Appetite 49, 66-73.

26. Jansen A, Nederkoorn C, van Baak L, et al. (2009) Highrestrained eaters only overeat when they are also impulsive. Behav Res Ther 47, 105-110.

27. Guerrieri R, Nederkoorn C, Schrooten M, et al. (2009) Inducing impulsivity leads high and low restrained eaters into overeating, whereas current dieters stick to their diet. Appetite 53, 93-100.

28. Rotenberg KJ, Lancaster C, Marsden J, et al. (2005) Effects of priming thoughts about control on anxiety and food intake as moderated by dietary restraint. Appetite 44, 235-241.

29. Herman CP \& Polivy J (2008) External cues in the control of food intake in humans: the sensory-normative distinction. Physiol Behav 94, 722-728.

30. Nijs IMT, Muris P, Euser AS, et al. (2010) Differences in attention to food and food intake between overweight/obese and normal-weight females under conditions of hunger and satiety. Appetite 54, 243-254.

31. Lochbuehler K, Voogd H, Scholte RHJ, et al. (2011) Attentional bias in smokers: exposure to dynamic smoking cues in contemporary movies. J Psychopharmacol 25, 514-519.

32. Field M, Eastwood B, Bradley BP, et al. (2006) Selective processing of cannabis cues in regular cannabis users. Drug Alcohol Depend 85, 75-82.

33. Patton JH, Stanford MS \& Barrat ES (1995) Factor structure of the Barratt Impulsiveness Scale. J Clin Psychol 51, 768-774.

34. Logan GD, Schachar RJ, Tannock R, et al. (1997) Impulsivity and inhibitory control. Psychol Sci 8, 60-64.

35. Nederkoorn C, Houben K, Hofmann W, et al. (2010) Control yourself or just eat what you like? Weight gain over a year is predicted by an interactive effect of response inhibition and implicit preference for snack foods. Health Psychol 29, 389-393.

36. Anschutz DJ, Engels RCME, Becker ES, et al. (2009) The effects of TV commercials using less thin models on young women's mood, body image and actual food intake. Body Image 6, 270-276.

37. Hermans RCJ, Herman CP, Larsen JK, et al. (2010) Social modeling effects on snack intake among young men. The role of hunger. Appetite 54, 378-383.

38. Cohen J (1988) Statistical Power Analysis for the Behavioural Sciences, 2nd ed. Hillsdale, NJ: Lawrence Erlbaum.

39. Hermans RCJ, Engels RCME, Larsen JK, et al. (2009) Modeling of palatable food intake. The influence of quality of social interaction. Appetite 52, 801-804.

40. Rolls BJ, Rolls ET \& Rowe EA (1982) The influence of variety on human food intake and selection. In The Psychobiology of Human Food Selection, pp. 101-122 [LM Barker, editor]. Westport, CT: AVL. 
41. Feeney JR, Polivy J, Pliner P, et al. (2011) Comparing live and remote models in eating conformity research. Eat Behav 12, 75-77.

42. Polivy J, Herman CP \& Younger JC (1979) Effects of a model on eating behavior. Induction of a restrained eating style. J Pers 47, 100-117.

43. Vartanian LR, Herman CP \& Wansink B (2008) Are we aware of the external factors that influence our food intake? Health Psychol 27, 533-538.

44. Deutsch M \& Gerard HB (1955) A study of normative and informational social influences upon individual judgement. J Abnorm Psychol 51, 629-636.

45. Roth DA, Herman CP, Polivy J, et al. (2001) Selfpresentational conflict in social eating situations: a normative perspective. Appetite 36, 165-171.

46. Vartanian LR, Herman CP \& Polivy J (2007) Consumption stereotypes and impression management: how you are what you eat. Appetite 48, 265-277.

47. Braet C, Claus L, Verbeken S, et al. (2007) Impulsivity in overweight children. Eur Child Adolesc Psychiatry 16, 473-483.

48. Nederkoorn C, Braet C, Van Eijs Y, et al. (2006) Why obese children cannot resist food: the role of impulsivity. Eat Behav 7, 315-322.
49. Lijffijt M, Bekker EM, Quik EH, et al. (2004) Differences between low and high trait impulsivity are not associated with differences in inhibitory motor control. J Atten Disord $\mathbf{8}, 25-32$.

50. Guerrieri R, Nederkoorn C \& Jansen A (2008) The interaction between impulsivity and a varied food environment: its influence on food intake and overweight. Int $J$ Obes 32 , 708-714.

51. Smeets E, Roefs A \& Jansen A (2009) Experimentally induced chocolate craving leads to an attentional bias in increased distraction but not in speeded detection. Appetite 53, $370-375$.

52. Franken IHA \& Muris P (2005) Individual differences in reward sensitivity are related to food craving and relative body weight in healthy women. Appetite 45, 198-201.

53. Tapper K, Pothos EM, Fadardi JS, et al. (2008) Restraint, disinhibition and food-related processing bias. Appetite 51, $335-338$.

54. Strack F, Werth L \& Deutsch R (2006) Reflective and impulsive determinants of consumer behavior. J Consum Psychol 16, 205-216. 